\title{
Two-Dimensional Gel Electrophoresis (2-DE)
}

\author{
Bruno Baudin \\ Faculty of Pharmacy, Châtenay-Malabry, Paris Sud University \\ Biochemistry Laboratory, Saint-Antoine Hospital, APHP, Paris,
}

France

\section{Introduction}

Two-dimensional gel electrophoresis (2-DE) is able to separate hundreds to thousands of proteins or polypeptides by coupling IsoElectric Focusing (IEF) in first dimension and Sodium Dodecyl Sulphate PolyAcrylamide-Gel Electrophoresis (SDS-PAGE) in second dimension. This particular configuration is called classical 2-DE: IEF separates proteins in function of their isoelectric point (pI) and SDS-PAGE in function of their molecular mass $(\mathrm{Mr})$, these two parameters being unrelated; the second dimension can be also Native PAGE. In other configurations, Native PAGE is the first dimension and SDS-PAGE the second one. Classical 2-DE is still the core technique in proteomics as the first step to separate complex protein mixtures, the second step being the identification of these separated polypeptides using mass spectrometry, either with peptide mass fingerprinting (PMF) after specific proteolytic hydrolysis (for MALDI-TOF or ESI-TOF mass spectrometry), or with sequencing of the polypeptide chain using liquid chromatography coupled to tandem mass spectrometry (LC-MS/MS). Classical 2-DE has also direct applications, such as phenotyping of genetic variants and post-translational modification (PTM) characterization, in particular phosphorylations, glycosylations, deamidations and much more. This chapter will describe the main 2-DE techniques with some developments on IEF, Native PAGE as first or second dimension, and SDS-PAGE as second dimension in proteomic analysis.

\section{Classical 2-DE}

For the separation of complex protein mixtures, 2-DE is one of the main techniques that can reveal hundreds and even thousands of proteins at a time. The classical 2-DE approach combines IEF in first dimension and SDS-PAGE in second dimension.

\subsection{Sample preparation}

\subsubsection{From cells or tissues}

The sample treatment is the key to obtain reasonable results. The protein composition of the cell lysate must be reflected in the pattern of the 2-D gel without any losses or modifications. Too much salt, like washing cells with PBS, and amphoteric buffers in cell cultures, like HEPES, have to be avoided. The chemicals used have to be of the highest purity. A typical denaturing buffer ("lysis buffer") is $9 \mathrm{M}$ urea, or $7 \mathrm{M}$ urea plus $2 \mathrm{M}$ thiourea, 2-4\% non-ionic 
or zwitterinonic detergent, $1 \%$ dithiothreitol (DTT) and 0.5\% carrier ampholytes. The high urea/thiourea concentration is needed to get proteins into a single conformation by cancelling the secondary and tertiary structures, to get hydrophobic proteins into solution, and to avoid protein-protein interactions. Thiourea improves the solubility of membrane proteins. CHAPS (3-(3-cholamidopropyl)dimethylammonio-1-propane sulphate), is a zwitterionic detergent, preferred to non-ionic polyol mixtures such as Triton X-100 and Nonidet P-40, because of its higher purity; it particularly increases the solubility of a number of hydrophobic proteins. DTT, or dithioerythreitol (DTE), prevents different oxidation steps of the proteins; 2- mercaptoethanol should not be used, because of its buffering effect above pH 8. Carrier ampholytes improve the solubility of proteins by substituting ionic buffers; they do not disturb the IEF step because they migrate to their pIs, where they become uncharged. They are not longer used to establish the $\mathrm{pH}$ gradient; this is today done with Immobilized pH Gradients (IPGs), such as with Immobilines ${ }^{\circledR}$. Bromophenol is very useful as a control dye. Nucleic acids, lipids, and salts must be removed; for example, salts can be removed by dialysis or precipitation, lipids with an excess of detergent $(>2 \%)$, and nucleic acids by sonication, or specific extraction. PMSF (phenylmethylsulphonyl-fluoride) is frequently used as an inhibitor of proteolysis; it must be added to the sample prior to the reducing agent. Anti-protease cocktails containing other protease inhibitors are less toxic and more effective, but some of these inhibitors might lead to charge modifications of some proteins. Protein precipitation can be very effective for diluted samples or plant samples: the content of the cell lysate is precipitated with 10\% TCA (trichloroacetic acid) in acetone; the pellet is washed with acetone, dried under vacuum, and resuspended with lysis buffer. Moreover, the proteases are inhibited. Exceptionally, the tissue is boiled for 5 minutes in 1$2 \%$ SDS before they are diluted with lysis buffer, for example for plants or organisms with tough cells. Optimized procedures for different sample types do exist; however a general procedure is not available (Görg et al. 2000, Baudin \& Bruneel, 2004; Bruneel et al., 2005; Görg et al. 2009).

\subsubsection{From biological fluids}

Both blood plasma and serum can be used; the choice of the anticoagulant to obtain plasma samples is not yet standardized, but EDTA is often preferred because it does not interfere with IEF and acts as metalloprotease inhibitor as well. Then the plasma or the serum isolated after centrifugation is stored at $-80^{\circ} \mathrm{C}$ when possible. The urines must be sampled from either a specimen or the urines of 24 hours, centrifuged to eliminate the mineral and organic pellet, and stored at $-80^{\circ} \mathrm{C}$. The cerebrospinal fluid is better analyzed without storage; alternatively, it can be centrifuged and stored at $-80^{\circ} \mathrm{C}$. For other biological fluids, not any protocol is yet standardized (Lehmann et al., 2000).

\subsection{First-dimension isoelectric focusing (IEF)}

\subsubsection{Using tubes}

In the original method for high resolution 2-D electrophoresis according to O'Farrell (1975), the IEF step was carried out with carrier ampholytes generating $\mathrm{pH}$ gradients in gel rods, as called "tube gels". Classically, the electric field is applied first to establish the pH gradient; then, the sample is loaded onto the acidic end of the gradient, the electric field is applied 
again to separate the proteins during the gradient drift to the cathode, and the run is stopped after a defined time period (Fig. 1). These gradients become unstable and drift with time; this effect is called "cathodal drift"; consequently, most of basic proteins are lost. A remedy was the modification of the IEF step with the use of non-equilibrium $\mathbf{p H}$ gradient electrophoresis (NEPHGE). Without real focalisation of proteins in this technique, the resolution of classical IEF cannot be achieved; moreover, due to the time factor, the reproducibility is decreased in comparison with classical IEF on flatbed system (Westermeier, 2001).

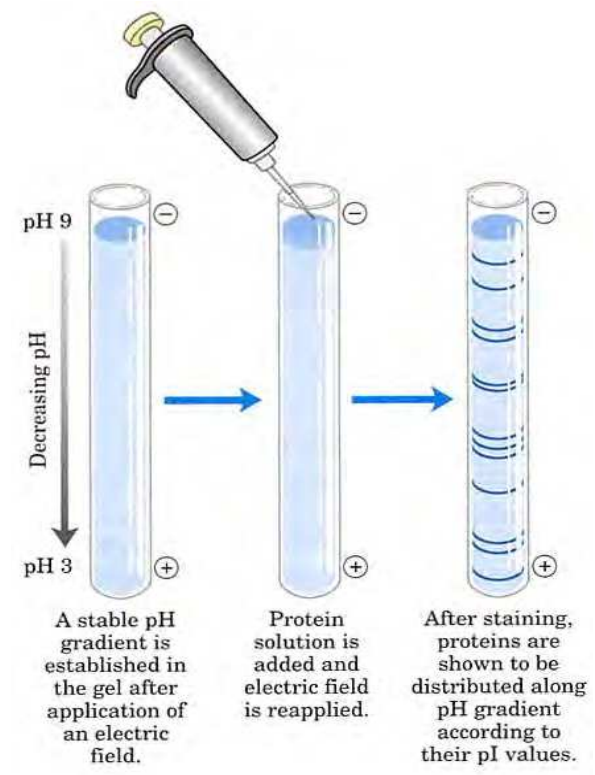

Fig. 1. IEF in tubes (a stable $\mathrm{pH}$ gradient is established in the gel by addition of appropriate ampholytes).

\subsubsection{Using flatbed system}

Horizontal (flatbed) polyacrylamide (PA) systems have a number of advantages over the vertical ones when ultrathin gels polymerized on support films are used, and particularly for IEF. Handling is simple, in particular for staining, washing, dehydration of the gel; ready-made gels are available with or without IPG; buffer strips are used instead of large buffer volumes; cooling is easy to perform efficiently. The same denaturing buffer as above can be used for sample loading, usually by a strip rehydrated with the sample then laid down on the acidic part of the gel. Agarose gels for IEF are now available because the agaropectin residues have been removed; however, the electro-endosmosis flow is not completely eliminated. Separations in agarose gels, usually containing $0.8-1.0 \%$ agarose, are more rapid than PA gels. Macromolecules larger than $500 \mathrm{kDa}$ can be separated since agarose pores are larger than those of PA gels. Moreover, its components are not toxic and cannot interfere with the separation. Nevertheless, it is difficult to prepare stable agarose 
gels with high urea concentrations because urea disrupts the configuration of the helicoidal structure of the polyoside chains. As well as with PA and agarose gels, IEF must be carried out at a constant temperature, usually $10^{\circ} \mathrm{C}$. Exceptionally, the temperature can be stated at $37^{\circ} \mathrm{C}$, for example for the study of cryoprotein, such as IgM, increasing their solubility, or at below $0^{\circ} \mathrm{C}$ for the analysis of ligand bindings or enzyme-substrate complexes. It is recommended to use marker proteins of known $\mathrm{pH}$ for controlling the $\mathrm{pH}$ gradient. The $\mathrm{pIs}$ of the proteins in sample can be measured on the $\mathrm{pH}$ calibration curve. Flatbed systems can use both concepts for establishing $\mathrm{pH}$ gradients, i.e. carrier ampholytes and immobilized pH gradients (IPGs)(Fig. 2a). When an electric field is applied, the negatively charged carrier ampholytes migrate towards the anode, the positively charged ones to the cathode. They align themselves in between according to their $\mathrm{pI}$ and will determine the $\mathrm{pH}$ of their environment. To maintain a gradient as stable as possible, strips of filter paper soaked in the electrode solution are applied between the gel and the electrodes (an acidic solution at the anode, and a basic solution at the cathode); nevertheless, these electrode solutions are not necessary for short gels. Carrier ampholytes are also very useful for preparative separations and titration curve analysis. Problems with carrier ampholytes can arise when long focusing times are necessary. First, as with tubes the cathodal drift can take away part of the proteins out of the gel. Moreover, a gel can burn through at the conductivity gaps, in particular created when highly viscous additives are used. Because of some limitations of the carrier ampholytes system, an alternative method was developed: IPGs. They are built with acrylamide derivatives with buffering groups, as called Immobilines ${ }^{\circledR}$, by copolymerization of the acrylamide monomers in a PA gel (Fig. 2b). To be able to buffer at a precise $\mathrm{pH}$ value, at least two Immobilines are necessary, an acid and a base. A pH gradient is obtained by the continuous change in the ratio of Immobilines. In practice, IPGs are prepared by linear mixing of two different polymerization solutions with a gradient maker, as for pore gradients. Since the gradient is fixed in the gel, it stays unchanged all along the separation time even with viscous additives such as urea and non-ionic detergents. IPG can be exactly calculated in advance and adapted to the separation problem reaching very high resolution with up to $0.01 \mathrm{pH}$ units per $\mathrm{cm}$. The gradient is not influenced by proteins and salts in the solution. The use of IPGs is restricted to PA gels only. New IEF systems try to expand the $\mathrm{pH}$ range in both directions by using very acidic or basic narrow $\mathrm{pH}$ gradients; they are based on additional types of Immobilines. IPGs can also be used with a perpendicular urea gradient to detect various mutations in proteins, and for preparative separations. But, flatbed IEF, even being the best classical IEF system, is really not well adapted for fist dimension of 2-DE; dry strips are most often preferred (Westermeier, 2001; Baudin, 2010).

\subsubsection{Using dry strips}

IEF is performed in $0.5 \mathrm{~mm}$-thin IPG-gel-strips cast on plastic backing. The film-supported gels are easy to handle; IPGs are very reproducible, in particular because the fixed gradients are not modified by the sample composition; moreover, detergents and reducing agents can be added without $\mathrm{pH}$ gradient disturbing. Samples are usually dissolved in denaturing buffer (for example in the lysis buffer described above), and then applied by cup loading or by in-gel rehydration. Protein losses due to aggregation and precipitation are avoided with sample loading by rehydration. Several strips can run in parallel, up to twelve using actual materials. Typically, by using 4-7 or 3-10 IPGs, highly resolved and reproducible 2D 
patterns can be obtained with more than 1000 spots in a $180 \times 200 \mathrm{~cm}$ gel for example, and from only some micrograms of sample. Some IPGs cover the acidic $\mathrm{pH}$ area whereas other IPGs are specific for basic proteins, $\mathrm{pH}$ 9-12 for example. But, as most proteins in a total cell lysate have pIs between 3 and 7, the acidic $\mathrm{pH}$ gradients are often preferred, such as 3-7 or 47 for example. Narrow $\mathrm{pH}$ gradients (such as 4-5, 4.5-5.5, and even in $0.2 \mathrm{pH}$ units with $\mathrm{pH}$ 4.35-4.55 gradient) can be overlapped increasing the number of detected spots (Fig. 3); they are well applied to micro-preparative separations with sample loads of up to several milligrams (Westermeier et al., 1983; Görg et al., 2009).

a)

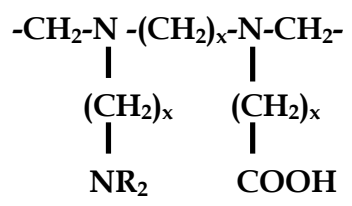

$$
\begin{gathered}
\mathrm{R}=\mathrm{H} \text { or }\left(\mathrm{CH}_{2}\right)_{\mathrm{x}}-\mathrm{COOH} \\
\mathrm{x}=2 \text { or } 3
\end{gathered}
$$

b)

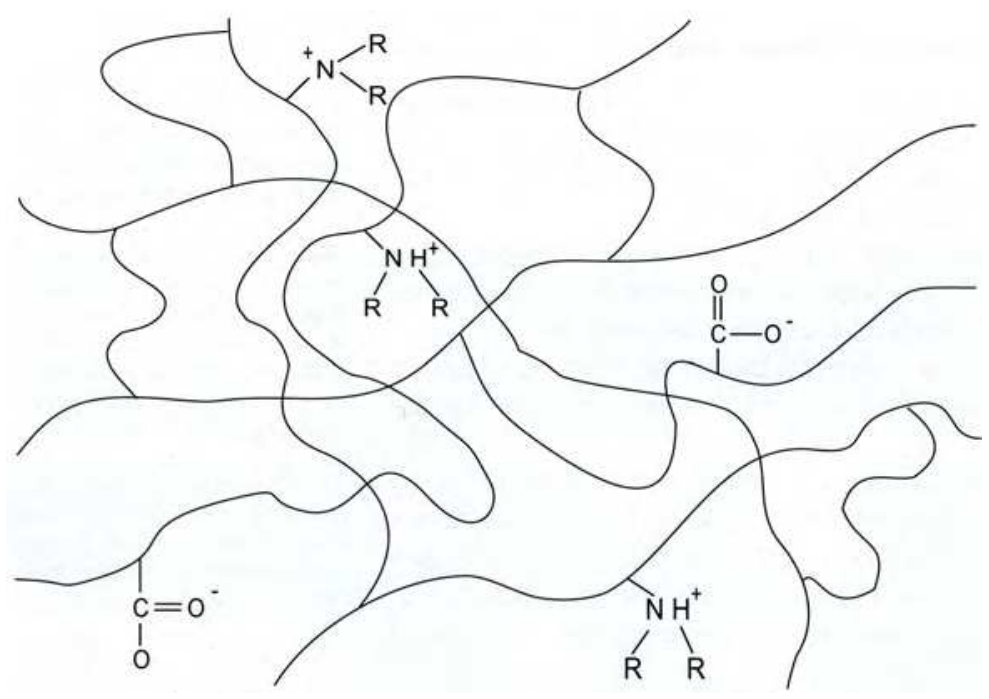

Fig. 2. Carrier ampholytes for IEF analysis. a) General formula of ampholytes; b) Schema of polyacrylamide network with co-polymerized Immobilines.

\subsection{Second-dimension SDS-PAGE}

Before the second dimension, the IPG strips are equilibrated in the specific buffer adapted to SDS-PAGE separation, in particular with reducing agent such as DTT or DTE, and by iodoacetamide to block the thiol groups by alkylation; finally, the strip is equilibrated in Tris buffer, plus urea, glycerol, and SDS. SDS-PAGE is then performed on either horizontal or 
vertical systems. The latter is preferred for multiple runs in parallel. Hydrophobic proteins are difficulty studied with classical 2-DE because they cannot enter the gel of first dimension; in that case, Native PAGE is the preferred technique.

\subsubsection{Using vertical electrophoresis}

A stacking gel is not needed when proteins are separated in first dimension with IEF run on strip; proteins can migrate from a gel to another gel. Classical procedures can be used for SDS-PAGE, in particular according to Laemmli (1970) in a Tris-chloride/Tris-glycine buffer system or according to Schägger \& von Jagow (1987) for small peptides in Tris-tricine gels. The concentration of acrylamide can be chosen, typically at $12 \%$ or in gradient such as between 8 and 18\% for proteomic studies. Usually, 1 to $1.5 \mathrm{~mm}$ thick SDS-PA gels are used; the IPG-strip is placed on the SDS gel edge. But, highly abundant proteins can form gel ridges. Up to 12 gels can run in parallel, but care must be taken with the gels because they can easily be broken into pieces; moreover, once a gel leaves the glass cassette after the run, it tends to swell and shrink during staining.

\subsubsection{Using flatbed system}

Horizontal flatbed systems can be used with similar results. The temperature has to be regulated, for example with a cooling plate. Film-supported SDS PA gels for the second dimension are much easier to use. Another advantage of flatbed systems is the facilitated image analysis. Nevertheless, the steps in silver staining require more time, and the film can show fluorescent background at certain wavelengths.

\subsubsection{High-resolution 2-DE}

For the complex protein mixtures, high-resolution and high purity of spots can solely be achieved by adequate special resolution using large gel sizes (up to $1 \mathrm{~m}$ ). Less complex protein mixtures are usually studied in medium sizes to miniformate gels. The latter are useful for optimization of sample preparation. There are ready-made gels available for large and small formats (Weiss \& Görg, 2009).

\subsubsection{Other second dimension}

Native PAGE is an alternative to SDS-PAGE as a second dimension for 2-DE. This method allows the separation of membrane proteins solubilised with non-ionic detergents, which could interfere with SDS; native PAGE can solve this problem (Schägger \& von Jagow, 1991). Coomassie Blue G-250 is added to the cathodal buffer in the vertical chamber of a native PAGE; during the run the dye competes with the non-ionic detergent and binds to the membrane proteins charging them negatively as made by SDS. All these complexes migrate to the anode; aggregation between proteins is minimized. These gels do not need to be stained, because the proteins migrate as blue bands. When a cationic detergent is used for membrane protein solubilisation, strongly acid proteins do not bind SDS and behave abnormally in SDS gels. An alternative is to use cationic detergents such as cetyltrimethylammonium bromide (CTAB), at pH 3 to 5, allowing a separation according to the molecular mass in the direction of the cathode. CTAB causes less damage to the protein than SDS, and particularly to enzymes, that can be used in a native PAGE system (Atin et al., 1985). 


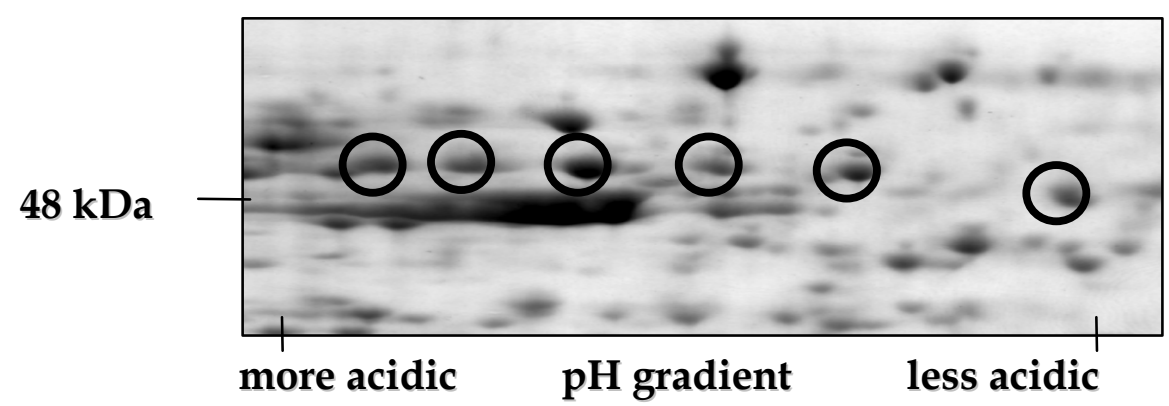

Fig. 3. Separation of six endo-protein-disulfide-isomerase (endothelial PDI) isoforms (circles) in human umbilical vein endothelial cells (HUVECs) using narrow gradient IEF in first dimension and dry-strip (personal communication).

\subsection{Visualizing and evaluating results}

\subsubsection{Labelling and staining}

After the electrophoresis is complete, the resolved proteins can be detected by various techniques. The ideal detection system should be very sensitive, quantitative and compatible with the further analysis such as with mass spectrometry, have a wide linear dynamic range; it should be also relatively quick and not too expensive, and non-toxic... At now, none technique combines all these features. The most popular methods use chromophoric staining with Coomassie Brilliant Blue or silver nitrate; the former is easy to perform and shows good reproducibility but it is not very sensitive allowing the detection of only the major components of the protein mixture $(0.1 \mu \mathrm{g}$ per spot), whereas silver nitrate is up to 500 times more sensitive (0.2 ng per spot), but with poor reproducibility, a limited dynamic range and with the disadvantage that certain proteins stain poorly, even not at all; moreover, silver staining requires multiple steps. Colloidal Coomassie Blue (CCB) emerges as an alternative being more sensitive than classical Coomassie Blue staining, and particularly suitable for in gel digestion and identification of proteins by mass spectrometry in the classical 2-DE proteomic approach. It is very important that staining is performed in closed trays to prevent keratin contamination. Figure 4 illustrates a comparison between silver nitrate and CCB staining of the proteome of human endothelial cells cultured from the umbilical vein of newborns (HUVECs), and using classical 2-DE with IPG technology. Another example of Coomassie Blue staining is given figure 5 exhibiting major proteins in human serum. The large dynamic range of proteins in serum makes the analysis very challenging because high-abundant proteins tend to mask those of lower abundance. A prefractionation step, such as depletion of a few high-abundant proteins, can assist in the detection of less abundant proteins that may be informative biomarkers (Björall $\mathrm{K}$ et al., 2005). The same problem may arise from other biological fluids such as cerebrospinal fluid (CSF), as rich in albumin as serum (Roche, 2008). Negative staining with imidazole zinc is an alternative for staining with good sensitivity ( $15 \mathrm{ng}$ per spot) as only the background is stained, and not the proteins; but it cannot be used for quantification. Another alternative is the use of fluorophores, i.e. fluorescent dyes, such as cyanines for preelectrophosesis labelling, or Sypro-Ruby ${ }^{\circledR}$ for post-electrophoresis labelling, i.e. used like a chromophoric dye. Fluorescent dyes are much more sensitive than CCB but not than silver nitrate; they have very wide linear dynamic range. Most of actual fluorescent or coloured dyes 
are compatible with subsequent analysis by mass spectrometry, but not silver nitrate when aldehydes are used. Cyanines, now also other fluorescent dyes, are used for Difference Gel Electrophoresis $\left(\mathrm{DIGE}^{\circledR}\right)$ allowing direct comparison between different types of samples. Unfortunately, all these fluorescent dyes are expensive, and a fluorescent scanner or a CCD camera is required. Radio-labelling is possible, in particular after incorporation during translation, for example using ${ }^{35 S}$-Met-labelling or ${ }^{32} \mathrm{P}-\gamma-\mathrm{ATP}-\mathrm{labelling}$ for the study of phosphorylations. Radioactive detection is sensitive (less than 1 pg per spot) but suffers from long exposure times (up to several weeks) and limited dynamic range when autoradiography is performed. Stable isotopes $\left({ }^{14} \mathrm{~N} /{ }^{15} \mathrm{~N}\right.$-amino acids or ${ }^{12} \mathrm{C} /{ }^{13} \mathrm{C}$-glucose for example) can also be used; they are ideal for quantification, but are expensive and require high resolution mass spectrometry. Moreover, these labelling methods require living cells, and cannot be applied on analysis of body fluids or tissues. Blotting of 2-D gels is used for immunodetection. The transfer onto nitrocellulose or PVDF can be classically performed; a control of transfer efficacy is recommended, for example by staining the blot shield with Ponceau Red and/or the gel with Coomassie Blue to control protein disappearance (Baudin, 2010).

\subsubsection{Image capture and analysis}

In proteomic analysis, images of $2 \mathrm{D}$ gels are captured by scanning the $\mathrm{CCB}$ or silver nitrate stained gels, or by importing the files from a fluoro- or phosphor-imager when using fluorescent dye or radio-labelling, respectively. There is a convention how to display a 2-D gel: the acidic proteins (with low $\mathrm{pI}$ ) are shown on the left side, and the low molecular mass proteins at the bottom (see Fig. 3 and 4). Usually, the highest-quality gel is designed as the reference gel; in function of the number of experiments carried out in the series, mismatching can be corrected allowing comparisons to the reference gel. The information

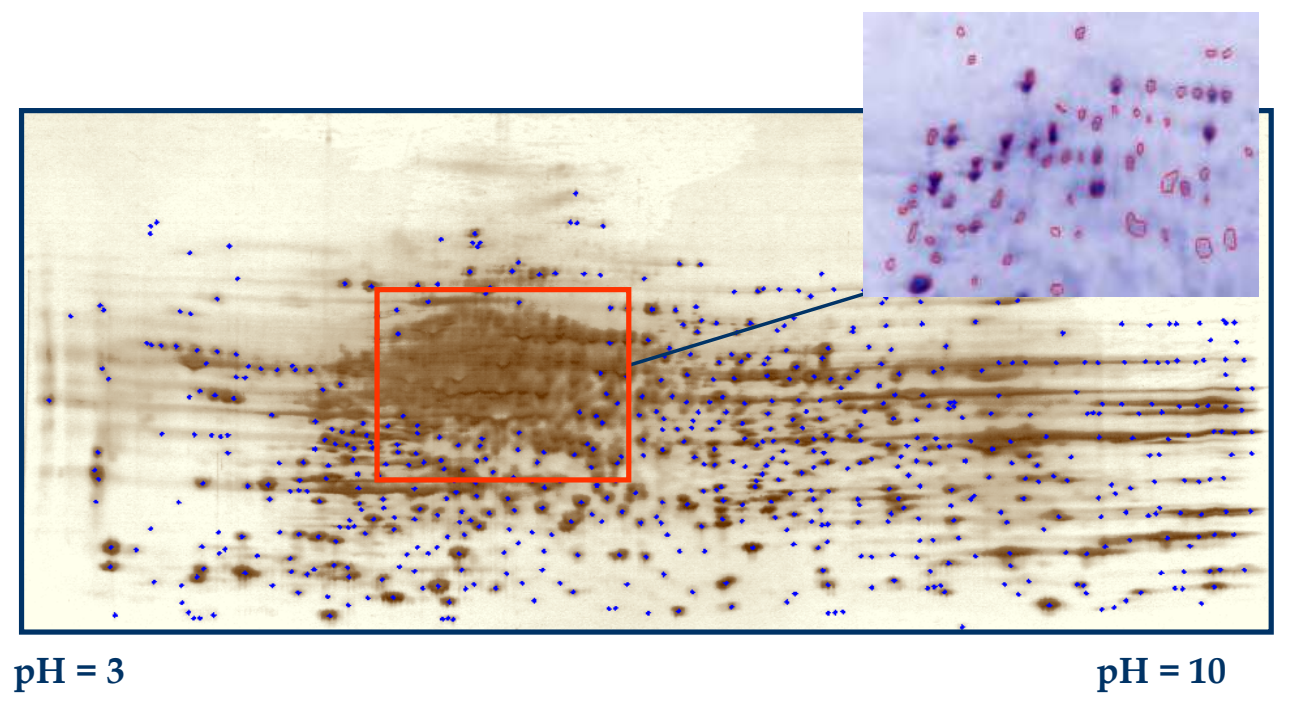

Fig. 4. Comparison between silver nitrate staining and Coomassie Brilliant blue staining of a 2-D gel separating proteins from HUVECs (IEF on IPG-strip $\mathrm{pH}$ gradient 3-10 and SDSPAGE on flatbed 8-18 \% PA)(personal communication). 


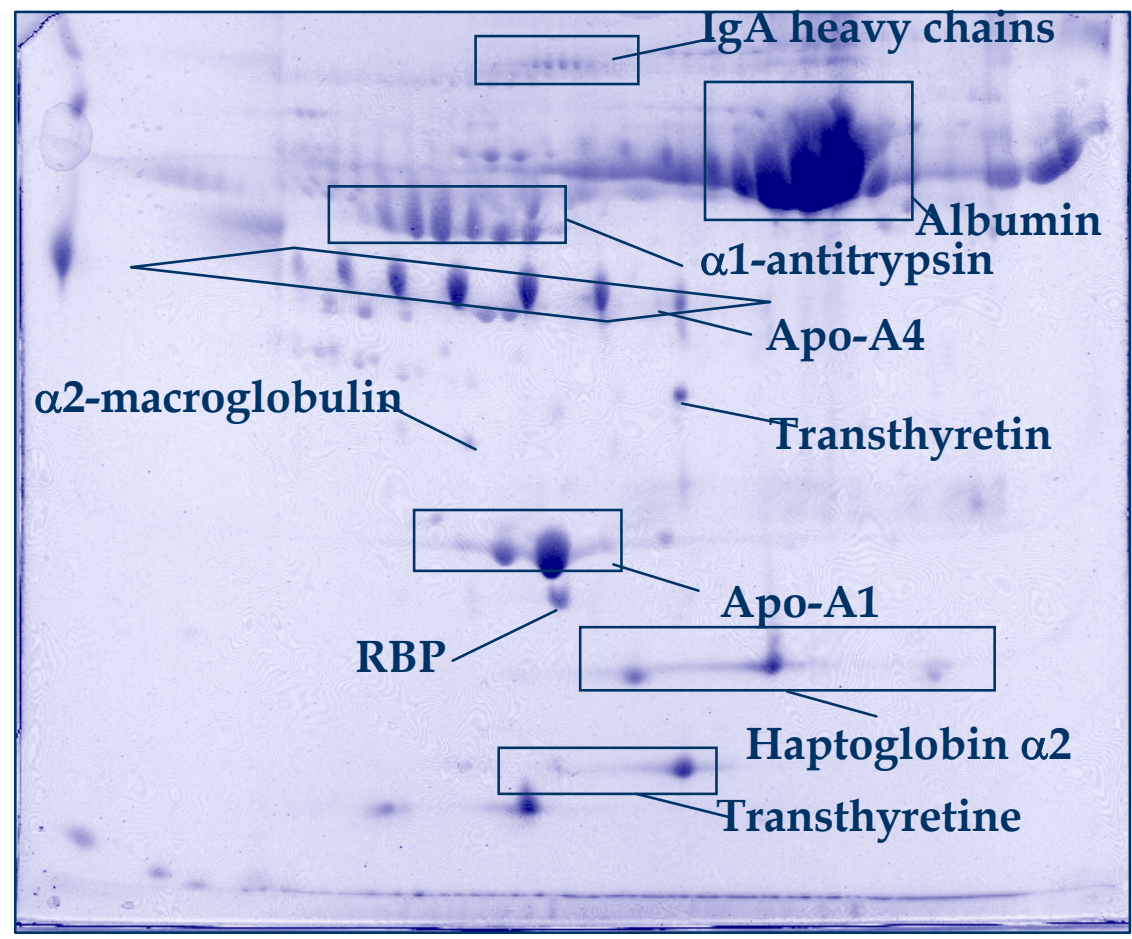

Fig. 5. 2-DE performed as in Fig. 3, but with a sample of human serum, and Coomassie Blue staining showing major plasma proteins (personal communication).
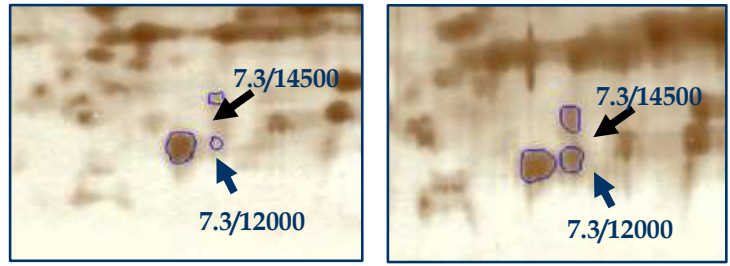

\section{Control}

\section{$0.1 \mathrm{mg} / \mathrm{ml}$}

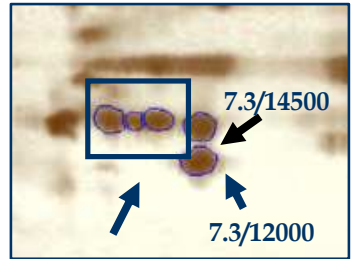

$1 \mathrm{mg} / \mathrm{ml}$

Fig. 6. Example of a proteomic analysis by 2-DE stained with silver nitrate (conditions as in Fig. 4): HUVECs were treated with etoposide at two concentrations, but not for control, showing the differential expression of proteins in the $\mathrm{pH}$ 7.2-7.3, $\mathrm{Mr} 12-15 \mathrm{kDa}$ area (personal communication). 
stored in the 2D-gel database can then be used to reveal qualitative and/or quantitative differences between individual samples, corresponding to over-expression of certain proteins or defect in other proteins (Fig. 6). Western-blotting can help to confirm an identity from peptide mass fingerprinting, either on another 2D gel or on other samples for classical $1 \mathrm{D}$ western-blotting. These tools allow differential expression studies and we can now assume that proteomics comes of age with protein identifications, functional characterizations and possible quantification by using particular new mass spectrometers. Protein spots are then identified with the help of genomic databases.

\subsubsection{Further analysis of protein spots}

In proteomics, the spots of interest are picked out the 2-D gel either manually with a scalpel, or automatically with a "spot-picker". Each piece of gel is dropped into a small tube for digestion in a buffer containing a protease, often trypsin for generating tryptic peptides; this step can be also automated (in a "digester"). The generated peptides are then extracted in acidic buffer for spotting on a MALDI-MS ("Matrix-Assisted Laser Desorption-Ionization Mass Spectrometry") plaque (for example automatically with a "spotter"), and finally analyzed with mass spectrometry (Fig. 7). MALDI-MS is suitable for Peptide Mass Fingerprinting (PMF)(Fig. 8) and offers automation for data acquisition and processing.

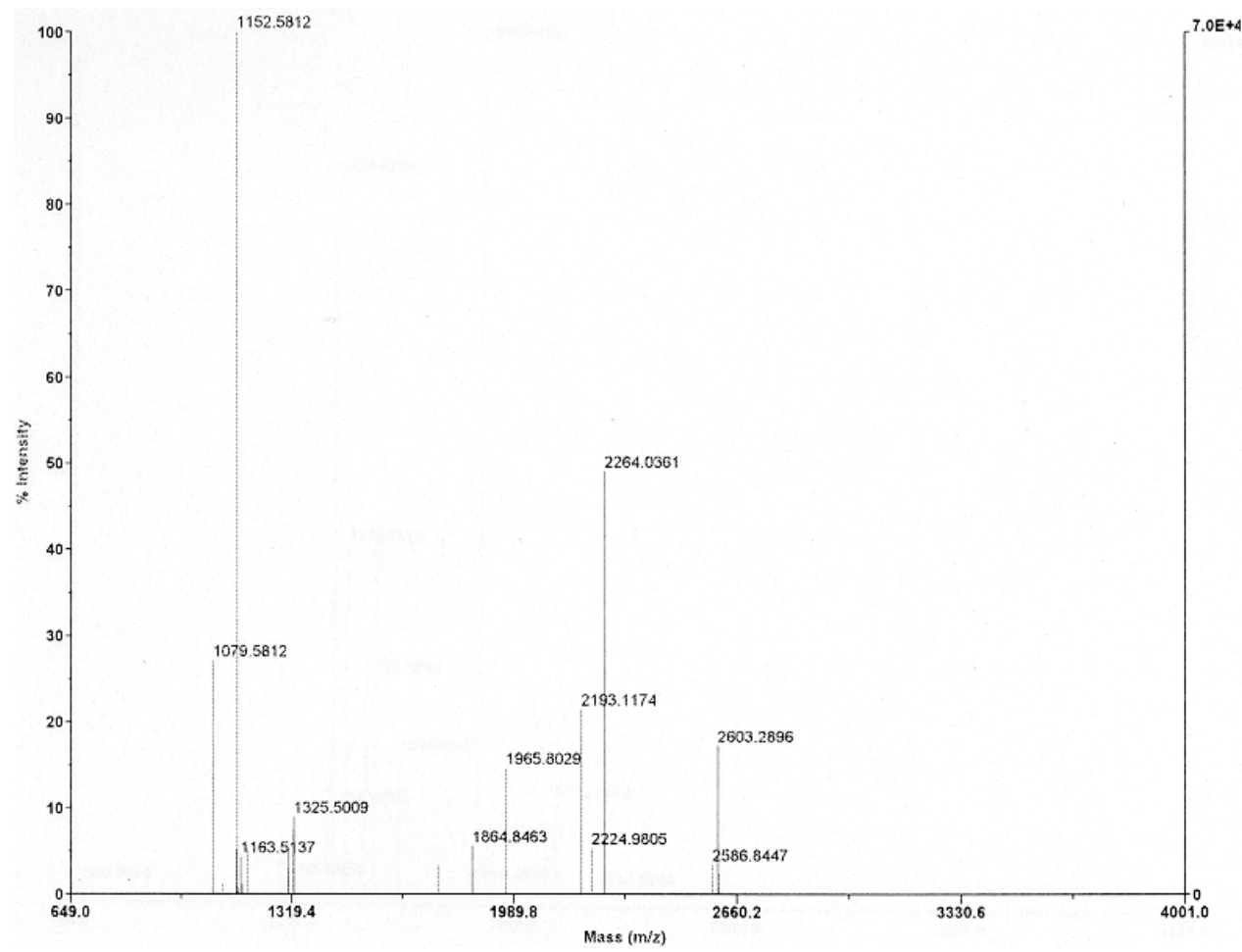

Fig. 7. MALDI-MS spectrum allowing the identification of endoPDI (see Fig. 3) by PMF (personal communication). 
Experimental data

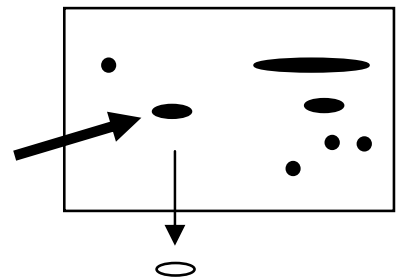

enzymatic digestion

$$
\text { peptides }
$$

$\underset{\text { spectrometry }}{\text { mass }}$
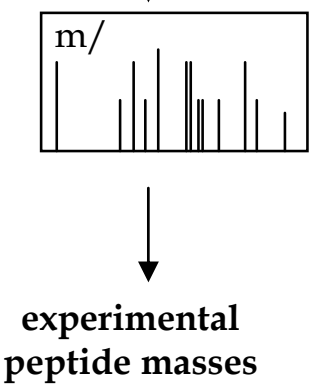

Databases

genome/protein sequencing

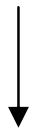

amino-acid sequences
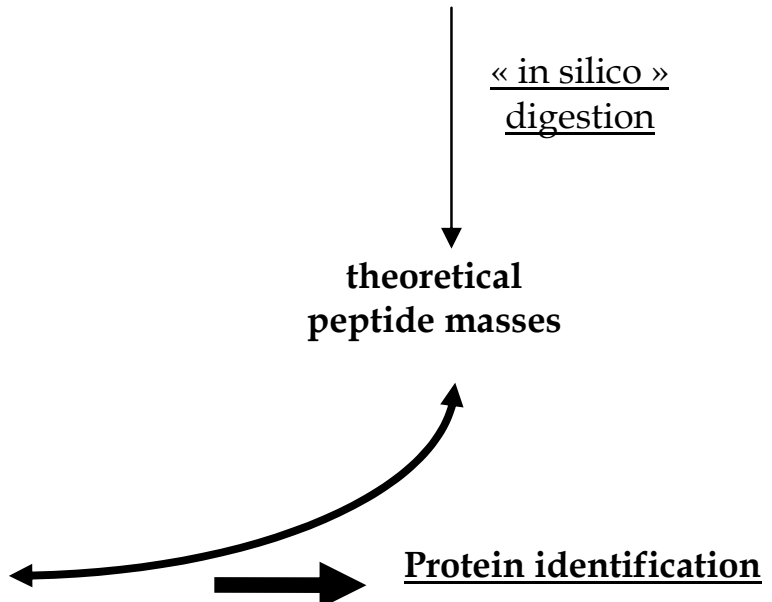

Fig. 8. The principle of Peptide Mass Fingerprinting (PMF) by mass spectrometry applied to a classical proteomic approach using 2-DE.

MALDI is usually performed on Time-on-Flight (TOF) mass analyzers which today incorporate both delayed extraction and reflectrons improving both resolution and mass accuracy. The mass of at least four or five peptides must be matched and $20 \%$ sequence coverage is required for protein identification with confidence. MALDI-MS is still as a cornerstone of proteomics, because the instrumentation is robust, relatively cheap and can be automated, then well adapted to high throughput. However, it has some limitations; in particular it cannot directly give sequence information, even when some good data emerged from the association of MALDI to a post-source decay or to another mass spectrometer in tandem (i.e. MALDI-TOF/TOF for example). ESI-MS is the second pillar of MS for proteomics; the tryptic peptides are separated by liquid chromatography for Electro Spray Ionization (ESI) and mass spectrometry analysis, in particular with a MS/MS analyser (LCESI-MS/MS), the second MS allowing sequencing the peptides. More precisely, the peptide ions generated in the spray are mono- or multi-charged (precursor ions, see Fig. 9) and separated in the first mass spectrometer; the most interesting precursor ions are selected and 
passed into the second mass spectrometer to deduce peptide sequence (Lahm \& Langen, 2000; Aebersold \& Mann, 2003; Baudin, 2010). Figure 10 gives an example of a website containing 2-DE data and the corresponding identifications using mass spectrometry either MALDI-MS or LC-ESI-MS/MS. Another alternative is the identification of proteins using western blotting that needs transfer from 2-D gel to a membrane and blotting with specific antibodies (Fig. 11). Some mass spectrometers are able to study PTM such as phosphorylation, also shown on 2-D gels, since this modification acidifies the proteins. Trypsin digestion generates phospho-peptides which can be measured by an increased mass of $39 \mathrm{Da}$. Other PTM such as glycosylations, deamidations, acetylations, methylations (and much more) can be also observed by specific modifications of the masses of the peptides (Mann \& Jensen, 2003).

\subsection{2-D fluorescence difference gel electrophoresis}

\subsubsection{D-DIGE}

Two Dimensional Difference Gel Electrophoresis (2D-DIGE ${ }^{\circledR}$ ) is a trademark from GEHealthcare; lysine-residues are labelled with different cyanine dyes (CyDyes) before 2-DE. Usually up to three different protein samples can be labelled with three different CyDyes, then mixed and separated in a single 2-DE. The composite 2D pattern is captured by a fluorescent scanner (such as Typhoon ${ }^{\circledR}$ fluoro-imager), or a CCD camera, and analyzed with accurate software that will show the differential expressions between the samples. That method is reproducible and sensitive at nanogram levels (Unlü et al., 1997). But, as the sensitivity of the dyes is high, another gel must be prepared with higher protein level and stained with CCB for classical PMF analysis or protein identification by sequencing.

\subsubsection{Other systems with fluorescent dyes}

Other fluorescent dyes are proposed by other manufacturers such as with the use of NHS ester-activated fluorescent dyes (DyeAGNOSTICS) avoiding interferences of fluorescence light emission featuring different molecular masses, and without transfer of fluorescence between dyes.

\section{Other 2-DE combinations}

Hydrophobic proteins such as membrane-bound proteins (class I or intrinsic membrane proteins) can be separated first in an acidic gel at $\mathrm{pH} 2.1$ in the presence of a cationic detergent followed by a SDS-PAGE in second dimension (Langen et al., 2000). For example, the benzyldimethyl-n-hexadecylammonium chloride (16-BAC) acts as a cationic detergent (like $\mathrm{CTAB}$, see above); at very low $\mathrm{pH}$, it binds to proteins and the detergent-protein complexes migrate to the cathode, when in second dimension SDS-protein complexes migrate to the anode, exhibiting different separation patterns. Native electrophoresis can also be run in amphoteric buffers; the catalysts of acrylamide polymerization (i.e. ammonium persulphate and TEMED) must be washed out of the PA gels used in horizontal systems with deionized water, because they would destabilize the buffer system. By equilibration with amphoteric buffers such as hydroxyethylpiperazine-ethanesulfonic acid (HEPES), N-morpholino-ethanesulfonic acid (MES) or N-morpholino-propanesulfonic acid (MOPS), PAGE can be run in native conditions (Westermeier, 2001). Proteins can be isolated 
<smiles>[R]C=[NH+]C(=O)C([R])N</smiles><smiles>[R]C([R])N([2H])C(=O)C#[O+]</smiles><smiles>[R]C(=O)C([R])([2H])NC([NH3+])=O</smiles><smiles></smiles><smiles>[R3]C([NH3+])C(=O)NC([R3])C(=O)O</smiles><smiles>[R9][CH]C(=O)NC([R1])C(=O)O</smiles>

Fig. 9. Major mono-charged dipeptidic ions (cations) generated in ESI-MS allowing peptide sequencing.

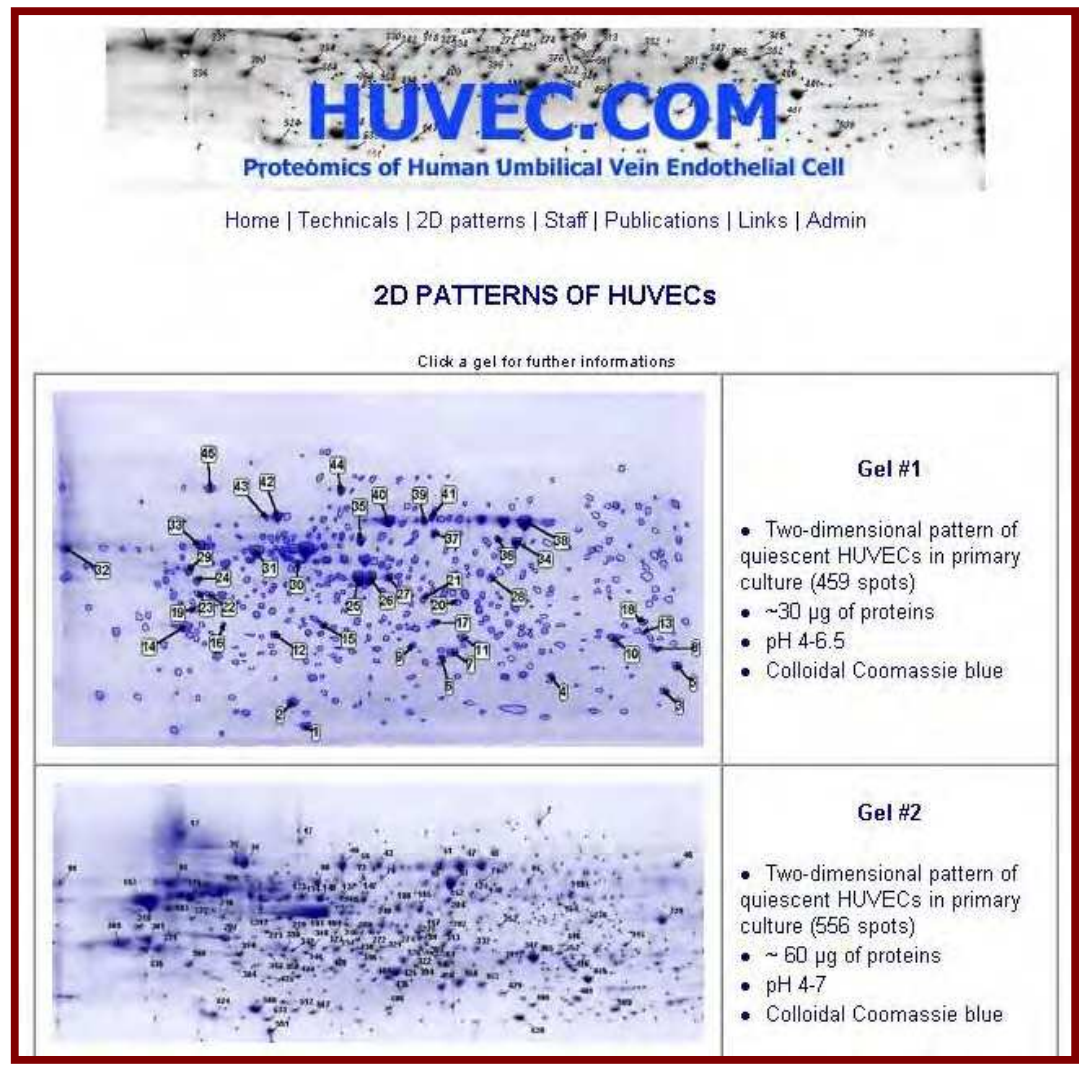

Fig. 10. Our web site on HUVEC proteomics (see http://www.huvec.com)(personal communication)(Pernet et al., 2006; Baudin et al., 2007). 
in enzymatically active forms when another native PAGE system is used in second dimension. Pre-fractionation of proteins is often necessary for a Native PAGE system used as first dimension, in particular for separating the protein partners in cellular complexes. This purification can be done with Free Flow Electrophoresis (FFE), an IEF method in liquid vein, or size exclusion chromatography (Baudin, 2010). The proteins constitutive of the complex are solubilised in a neutral detergent such as digitonin or dodecyl- $\beta \mathrm{D}$-maltoside; then, they can be applied to the chosen Native PAGE system using Coomassie Blue (for Blue native PAGE), or a cationic detergent such as 16-BAC or CTAB.

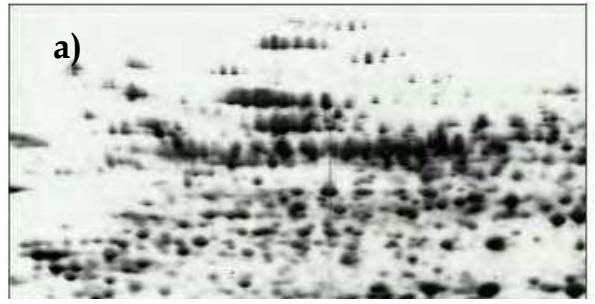

b)

Fig. 11. a) 2-DE with silver nitrate staining; b) Transfer of proteins from the 2-D gel onto nitrocellulose and identification of phosphotyrosyl-proteins detected selectively with antiphosphotyrosine antibodies (personal communication).

\section{Some applications of 2-DE}

Proteomics, which is the study of the entire protein complement expressed by a genome in a cell or a tissue, holds a key position in the new biology. It emerged from the long work on comprehensive protein visualisation on 2-D gels, in particular using mass spectrometry (MS) and revitalized by the development of peptide sequence databases. These tools allow differential expression studies with many applications as well as in fundamental biology as in medicine and pharmacology.

\subsection{To fundamental biology}

Many examples could be given showing the enormous amount of work which as been realized in cell biology. The complete proteome of Escherichia coli is now available; those of Helicobacter pylori, Salmonella sp., Bacillus subtilis, Mycobacterium tuberculosis, Mycoplasma pneumoniae, Haemophilus influenzae, and of many more other bacteria are in progress. In the biology of plants, Arabidopsis thaliana (a model for plant physiology study) proteome will be soon complete, as well as that of chloroplasts. In animal biology, main models are now more or less sequenced at the genomic level, and more or less completed at the proteome level, for example for Saccharomyces cerevisiae, Caenorhabditis elegans, Drosophila melanogaster, Xenopus laevis, Mus musculus and Homo sapiens sapiens (Celis et al., 1998; Baudin \& Bruneel, 2003). HUPO (Human Proteome Organization) has the ambition to determine the entire proteome of all the human tissues, such as blood plasma or serum (Fig. 5), and cell lines (Jung et al., 2000; Bruneel et al., 2003; Pernet et al., 2006).

\subsection{To medicine and drug discovery}

Proteomics represents a powerful approach of providing valuable information on target drug design, creating a new paradigm that will accelerate downstream drug development. 
Information at the level of the proteome is critical for understanding the function of specific cell types and their role in health and disease; mammalian systems are much more complex than be explained by their genes alone. Proteomics is also valuable in the discovery of biomarkers because the proteome reflects both intrinsic genetic program of the cell and the impact of its immediate environment. New biomarkers are needed to improve the diagnosis, the prognosis and the monitoring of diseases. For example, distinct changes occur during the transformation of a healthy cell into a neoplastic cell, ranging from altered expression, differential modifications, and changes in specific activities, to aberrant localization, all of which may affect cellular function. Particularly in cancer, it is useful to distinguish between diagnostic, prognostic, and predictive markers (Srinivas et al., 2001; Baudin \& Bruneel, 2003; Lehmann et al., 2007). Moreover, diagnostic markers are used to aid histopathological classification that is often a key for choosing between therapy modalities, including surgery, chemotherapy, radiotherapy and their combinations. Unfortunately, there are only a few markers which can predict treatment outcome. At least two approaches are available for cancer proteomics, one is the search of plasma markers; another is the examination of the tumour, for example using laser capture micro-dissection. Various protocols for solubilisation have been applied with or without enzymatic digestion, in particular with needle aspiration, surface scrapping or mincing of tumour tissue in buffer. Many examples could be given on the 2-DE analysis of tumours: in colorectal carcinomas, lung cancer, ovarian cancer, prostate cancer and leukaemia (Banks et al., 1999; Baudin \& Bruneel, 2003). Interesting data regularly emerge for the better understanding of the mechanisms of chemoresistance acquisition (Le Moguen et al., 2006, 2007; Klipfel-Froidevaux et al., 2011); an example of the discovery of potential biomarkers of chemoresistance is given figure 12 .

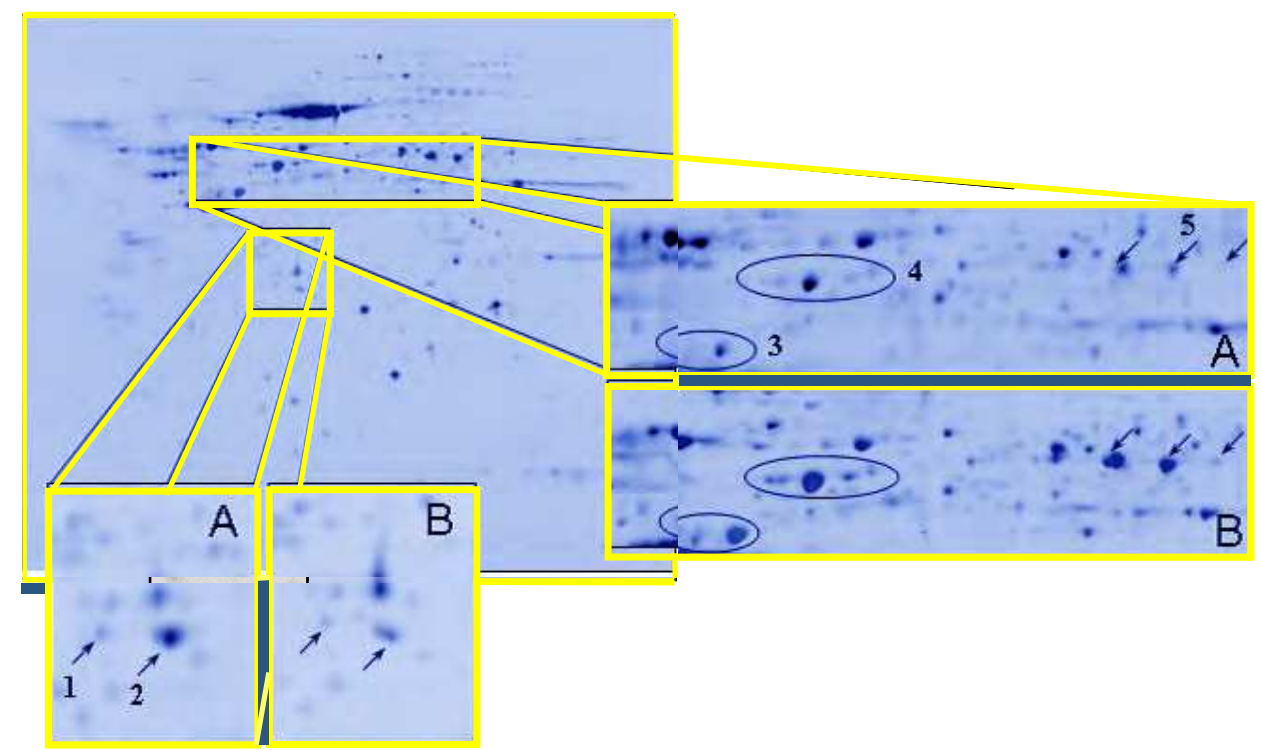

Fig. 12. Proteomics analysis of cisplatin resistance in an ovarian cancer cell line. Five proteins were identified by mass spectrometry after separation on 2-D gels stained with CCB, i.e. 1) annexin 3, 2) annexin 4,3) cytokeratin 18,4) cytokeratin 8, and 5) aldehydedehydrogenase 1; A) cisplatin sensitive cells, B) cisplatin resistant cells (personal communication)(Le Moguen et al., 2006). 

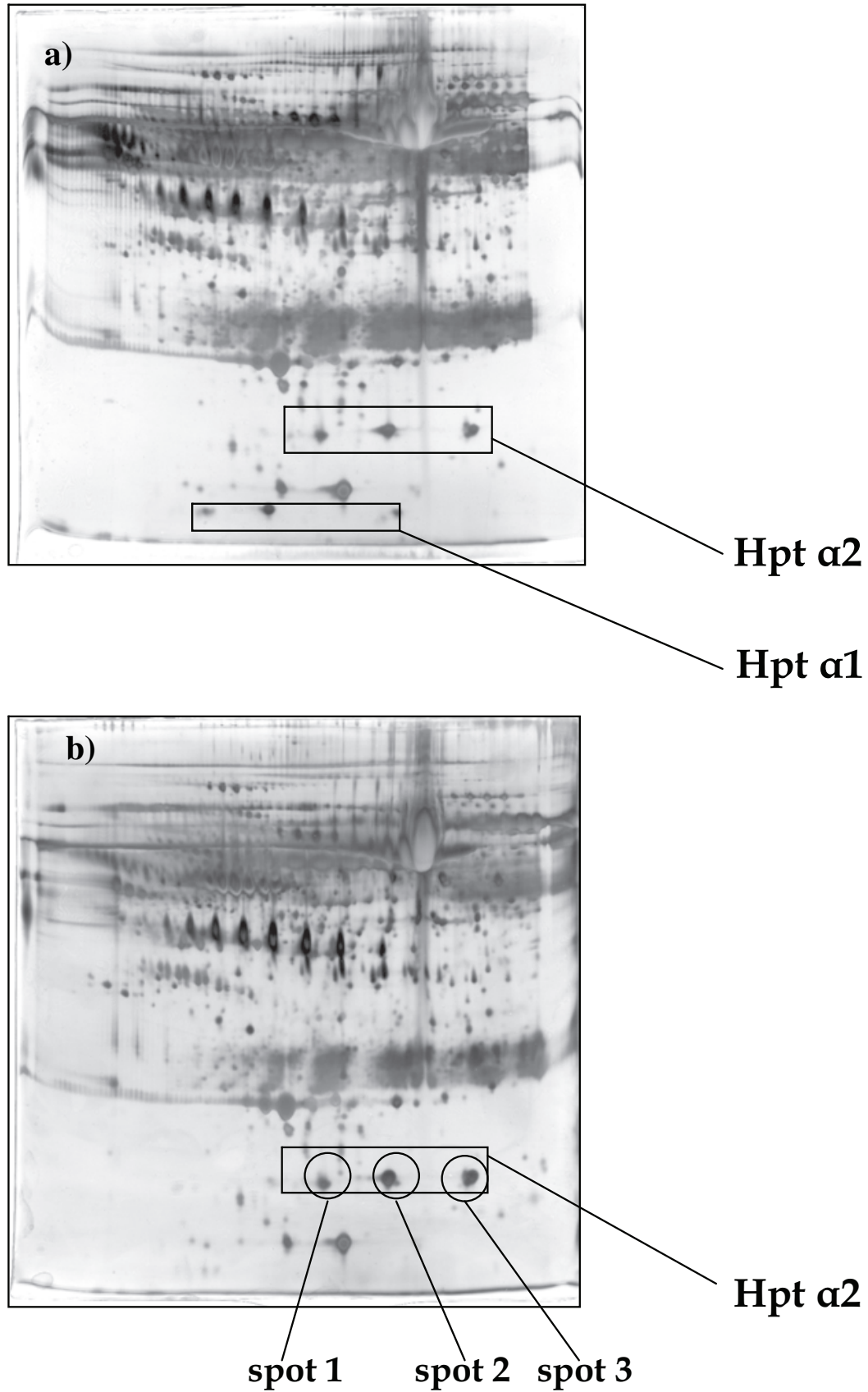

Fig. 13. Phenotyping of haptoglobin (Hpt) in human serum by 2-DE stained with silver nitrate; a) heterozygote $a 1 / a 2, b)$ homozygote $a 2 / a 2$ with characterization of isoforms in spots 1 and 2 (personal communication). 

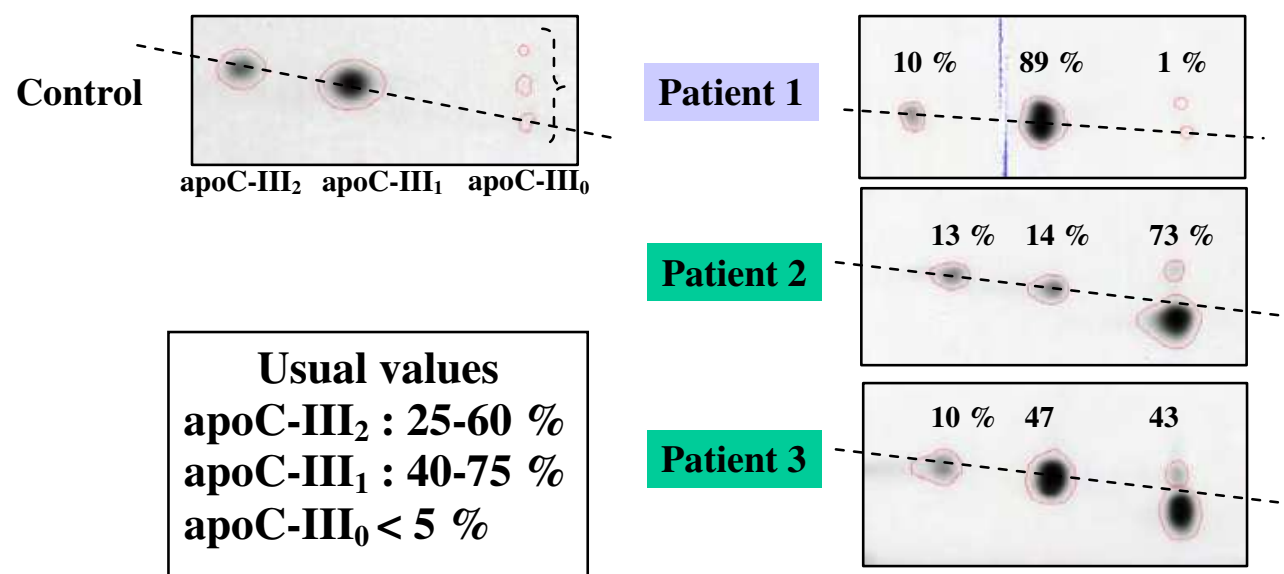

Fig. 14. O-glycosylations of serum apolipoprotein C-III isoforms in Congenital Disorders of Glycosylation (CDG); apoC-III 1 glycoform is monosialylated and apoC- III $_{2}$ glycoform is disialylated whereas apo-CIII ${ }_{0}$ is not sialylated; patients 2 and 3 exhibit high levels of desialylation, as confirmed by neuraminidase treatment (personal communication)(Bruneel et al, 2008).

Another approach is to work on biological fluids such as blood plasma, urines or cerebrospinal fluid (CSF)(Hu et al., 2006). More than 300 proteins have been characterized in human plasma by a classical 2-DE/MS approach (Anderson \& Anderson, 2002). New projects emerge for the detection and the quantification of all the minor proteins and peptides in plasma (Anderson NL et al., 2009; Ray et al., 2011). 2-DE can also be used directly for phenotyping major proteins in serum such as a1-antitrypsin or haptoglobin. We particularly studied by MALDI-TOF and Q-TOF (ESI-MS/MS) the PTM of haptoglobin (Hpt) a2: spot 1 at pI 5.39 is Hpt-2D5/E20, and spot 2 at pI 5.74 Hpt-2N5/E20, thus in spot 1 the asparagine $(\mathrm{N}) \mathrm{n}^{\circ} 5$ is deaminated in aspartate $(\mathrm{D})$ giving one more negative charge, i.e. more acidic; E20 is a glutamine equally present in both isoforms. Spot 3 could not be analyzed (Fig. 13).(personal communication). 2-DE is also able to study $\mathrm{N}$ - and $\mathrm{O}$ glycosylations (other PTMs), such as of major proteins in serum; an example is given figure 14 for the diagnosis of rare Congenital Disorders of Glycosylation (CDG), heterogeneous multisystem diseases sharing common features, thus needing an efficient biological screening (Bruneel et al., 2008).

\section{Conclusion}

2-DE can separate thousands of proteins with important features: it has extremely high resolving power, it can tolerate crude protein mixtures, and with relatively high sample loads; moreover, proteins separated in 2-D gels can be further analyzed. Most often, first dimension is IEF in an immobilized $\mathrm{pH}$ gradient, and second dimension is SDS-PAGE. Other combinations can be applied to more hydrophobic proteins, such as membranebound proteins, or high molecular mass proteins. Proteins can be identified by mass spectrometry, which is the core of proteomic analysis, using PMF with MALDI-TOF spectrometers or peptide sequencing with MS/MS. Confirmation of protein identity can be 
performed by western-blot either on the 2-D gel or using classical 1D-western-blotting but on another sample. The technique of 2-DE has been considerably improved during the past decades and new improvements regularly emerge from both industrial manufacturers and academic laboratories.

\section{Acknowledgement}

I would like to acknowledge Arnaud Bruneel for some of the pictures of 2-D gels and for his work on HUVECs, haptoglobin and CDG, Karen Le Moguen for some data on chemoresistance in ovarian cancer, and the team of Joëlle Vinh at ESPCI (USR3149-CNRS) in Paris for mass spectrometry analyses. I also acknowledge all the colleagues who help me to build the website on HUVECs, particularly Pascal Pernet at Saint-Antoine hospital in Paris.

\section{References}

Aebersold, R. \& Mann, M. (2003). Mass spectrometry-based proteomics. Nature Vol.422, pp. 198-207.

Anderson, N.L. \& Anderson, N.G. (2002). The human plasma proteome: history, character, and diagnostic prospects. Mol. Cell. Proteomics Vol.1, N¹1, pp. 845-867.

Anderson, N.L., Anderson, N.G., Pearson, T.W. et al. (2009). A human proteome detection and quantitation project. Molecular and Cellular Proteomics Vol.8, N5, pp. 883-886.

Atin, D.T., Shapira, R. \& Kinkade, J.M. (1985). The determination of molecular weights of biologically active proteins by cetyltrimethylammonium bromide-polyacrylamide gel electrophoresis. Analytical Biochemistry Vol.145, N¹, pp. 170-176.

Banks, R.E., Dunn, M.J., Forbes, M.A. et al. (1999). The potential use of laser capture microdissection to selectively obtain distinct populations of cells for proteomic analysis. Electrophoresis Vol.20, N²4-5, pp. 689-700.

Baudin, B. (2010). Protéomique, spectrométrie de masse et analyses multiples ( $\mathrm{N}^{0} 46$ ), Cahier de formation Bioforma Ed, Paris.

Baudin, B. \& Bruneel, A. (2004). Introduction to proteomics: Goals, technical aspects and applications to fundamental biology, drug discovery and clinical chemistry. Recent Research and Development in Biophysics and Biochemistry Vol.3, pp. 977-993.

Baudin, B. \& Bruneel, A., Bosselut, N. et al. (2007). A protocol for isolation and culture of Human Umbilical Vein Endothelial Cells (HUVECs). Nature Protocols Vol. 2, pp. 481-485.

Björhall, K., Miliotis, T. \& Davidson, P. (2005). Comparison of different depletion strategies for improved resolution in proteomic analysis of human serum samples. Proteomics Vol.5, pp. 307-317.

Bruneel, A., Labas, V., Mailloux, A. et al. (2003). Proteomic study of human umbilical vein endothelial cells in culture. Proteomics Vol.3, pp. 714-723.

Bruneel, A., Labas, V., Mailloux, A. et al. (2005). Proteomics of human umbilical vein endothelial cells applied to etoposide-induced apoptosis. Proteomics Vol.5, pp. 38763884 .

Bruneel, A., Morelle, W., Carre, Y. et al. (2008). Two dimensional gel electrophoresis of apolipoprotein C-III and MALDI-TOF MS are complementary techniques for the study of combined defects in N- and mucine type O-glycan biosynthesis. Proteomics Clinical Applications Vol. 2, pp. 1670-1674. 
Celis, J.E., Ostergaard, M., Jensen, N. et al. (1998). Human and Mouse databases: novel resources in the protein universe. FEBS Letters Vol.430, pp. 64-72.

Görg, A., Drews, O., Lück, C. et al. (2009). 2-DE with IPGs. Electrophoresis Vol.30, supplement 1, pp. S122-132.

Görg, A., Obermaier, C., Boguth, G. et al. (2000). The current state of two-dimensional electrophoresis with immobilized $\mathrm{pH}$ gradients. Electrophoresis Vol.21, N6, pp. 1037-1053.

Hu, S., Loo, J.A. \& Wong, D.T. (2006). Human body fluid proteome analysis. Proteomics Vol. 6, pp. 6326-6353.

Jung, E., Hoogland, C., Chiappe, D. et al. (2000). The establishment of a human liver nuclei two-dimensional electrophoresis reference map. Electrophoresis Vol.21, N¹6, pp. 3483-3487.

Klipfel-Froidevaux, L., Poirier, F., Boursier, C. et al. (2011). Modulation of septin and molecular motor recruitment in the microtubule environment of the Taxol-resistant human breast cancer cell line MDA-MB-231. Proteomics Vol.11, pp. 3877-3886.

Laemmli, U.K. (1970). Cleavage of structural proteins during the assembly of the head of bacteriophage T4. Nature Vol.227, N5259, pp. 655-664.

Lahm, H.W. \& Langen, H. (2000). Mass spectrometry: a tool for the identification of proteins separated by gels. Electrophoresis Vol.21, N¹1, pp. 2105-2114.

Langen, H., Tabacs, B., Evers, S. et al. (2000). Two-dimensional map of the proteome of Haemophilus influenzae. Electrophoresis Vol.21, N², pp. 411-429.

Lehmann, S., Dupuy, A., Peoc'h, K. et al. (2007). Présent et futur de la protéomique clinique. Annales de Biologie Clinique Vol.65, N5, pp. 463-471.

Le Moguen, K., Lincet, H., Deslandes, E. et al. (2006). Comparative proteomic analysis of cisplatin sensitive IGROV1 ovarian carcinoma cell line and its resistant counterpart IGROV1-R10. Proteomics Vol.6, pp. 5183-5192.

Le Moguen, K., Lincet, H., Marcelo, P. et al. (2007). A proteomic kinetic analysis of IGROV1 ovarian carcinoma cell line response to cisplatin treatment. Proteomics Vol.7, pp. 4090-4101.

Mann, M. \& Jensen, O.N. (2003). Proteomic analysis of post-translational modifications. Nature Biotechnologies Vol.21, pp. 255-261.

O'Farrell, P.H. (1975). High resolution two-dimensional electrophoresis of proteins. Journal of Biological Chemistry Vol.250, N¹0, pp. 4007-4021.

Pernet, P., Bruneel, A., Baudin, B. et al. (2006). A module for two-dimensional gel electrophoresis database creation on personal Web sites. Proteomics and Bioinformatics Vol.4, pp. 124-136.

Ray, S., Reddy, P.J., Jain, R. et al. (2011). Proteomic technologies for the identification of disease biomarkers in serum: advances and challenges ahead. Proteomics Vol.11, pp. 2139-2161.

Roche, S., Gabelle, A., Lehmann, S. (2008). Clinical proteomics of the cerebrospinal fluid: towards the discovery of new biomarkers. Proteomics and Clinical Biology Vol.2, pp. 428-436.

Schägger, H. \& von Jagow, G. (1987). Tricine-sodium dodecyl sulfate-polyacrylamide gel electrophoresis for the separation of proteins in the range from 1 to $100 \mathrm{kDa}$. Analytical Biochemistry Vol.166, N², pp. 368-379.

Schägger, H. \& von Jagow, G. (1991). Blue native electrophoresis for isolation of membrane protein complexes in enzymatically active form. Analytical Biochemistry Vol.199, No2, pp. 223-231. 
Srinivas, P.R., Srivastava, S., Hanash, S. et al. (2001). Proteomics in early detection of cancer. Clinical Chemistry Vol.47, N¹0, pp. 1901-1911.

Unlü, M., Morgan, M.E. \& Minden, J.S. (1997). Difference gel electrophoresis: a single gel method for detecting changes in protein extracts. Electrophoresis Vol.18, N¹1, pp. 2071-2077.

Weiss, W. \& Görg, A. (2009). High-resolution two-dimensional electrophoresis. Methods in Molecular Biology Vol.564, pp. 13-32.

Westermeier, R. (2001). Electrophoresis in practice (third edition), Wiley-VCH, ISBN 3-52730300-6, Germany.

Westermeier, R., Postel, W., Weser, J. et al. (1983). High-resolution two-dimensional electrophoresis with isoelectric focusing in immobilized $\mathrm{pH}$ gradients. Journal of Biochemical and Biophysical Methods Vol.8, N²4, pp. 321-330. 


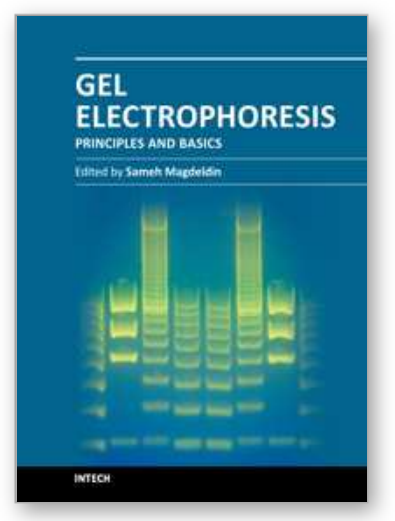

\author{
Gel Electrophoresis - Principles and Basics \\ Edited by Dr. Sameh Magdeldin
}

ISBN 978-953-51-0458-2

Hard cover, 346 pages

Publisher InTech

Published online 04, April, 2012

Published in print edition April, 2012

Most will agree that gel electrophoresis is one of the basic pillars of molecular biology. This coined terminology covers a myriad of gel-based separation approaches that rely mainly on fractionating biomolecules under electrophoretic current based mainly on the molecular weight. In this book, the authors try to present simplified fundamentals of gel-based separation together with exemplarily applications of this versatile technique. We try to keep the contents of the book crisp and comprehensive, and hope that it will receive overwhelming interest and deliver benefits and valuable information to the readers.

\title{
How to reference
}

In order to correctly reference this scholarly work, feel free to copy and paste the following:

Bruno Baudin (2012). Two-Dimensional Gel Electrophoresis (2-DE), Gel Electrophoresis - Principles and Basics, Dr. Sameh Magdeldin (Ed.), ISBN: 978-953-51-0458-2, InTech, Available from:

http://www.intechopen.com/books/gel-electrophoresis-principles-and-basics/two-dimensional-gelelectrophoresis

\section{INTECH}

open science | open minds

\section{InTech Europe}

University Campus STeP Ri

Slavka Krautzeka 83/A

51000 Rijeka, Croatia

Phone: +385 (51) 770447

Fax: +385 (51) 686166

www.intechopen.com

\section{InTech China}

Unit 405, Office Block, Hotel Equatorial Shanghai

No.65, Yan An Road (West), Shanghai, 200040, China

中国上海市延安西路65号上海国际贵都大饭店办公楼 405 单元

Phone: +86-21-62489820

Fax: +86-21-62489821 
(C) 2012 The Author(s). Licensee IntechOpen. This is an open access article distributed under the terms of the Creative Commons Attribution 3.0 License, which permits unrestricted use, distribution, and reproduction in any medium, provided the original work is properly cited. 